\title{
CONTRIBUTION OF EPIET TO PUBLIC HEALTH WORKFORCE IN THE EU, $1995-2008$
}

\author{
A Bosman (Arnold.Bosman@ecdc.europa.eu)1, B Schimmer ${ }^{2,3}$, D Coulombier ${ }^{1}$ \\ 1. European Centre for Disease Prevention and Control, Stockholm, Sweden \\ 2. Rijksinstituut voor Volksgezondheid en Milieu (National Institute for Public Health and Environment, RIVM), Bilthoven, \\ the Netherlands \\ 3. EPIET Alumni Network (EAN)
}

This article was published on 29 October 2009 .
Citation style for this article: Bosman A, Schimmer B, Coulombier D. Contribution of EPIET to public health workforce in the EU, 1995-2008. Euro Surveill.

2009;14(43):pii=19381. Available online: http://www.eurosurveillance.org/ViewArticle.aspx?ArticleId=19381

We analyse activities and outputs of fellows of the European Programme for Intervention Epidemiology Training (EPIET) between 1995 and 2008 and describe the employment history of graduates after the training to demonstrate the contribution of this programme and of national EPIET-associated programmes to the public health workforce in the European Union and Norway. Up to 2008, some 161 fellows entered the training: 121 in EPIET and 40 in EPIET-associated programmes. Of these 149 were awarded a diploma. Fellows engaged in projects in all areas of surveillance, in outbreaks and field investigations and produced 340 publications in peer-reviewed journals. Seventy fellows were sent to 98 individual assignments on 65 international missions. The vast majority of graduates (90\%) take up a position and remain employed in applied public health, either on regional, national or international level. Several (27) are working outside the EU, all in public health, including 13 working in Switzerland for international organisations. Only three of the 12 EU Member States that joined the EU since 2004, employ EPIET graduates. A major challenge for training the public health workforce is the retention of professionals in countries with limited job opportunities or wages significantly below the EU average.

\section{Introduction}

In order to increase the capacity to respond to emerging and ongoing threats from communicable diseases the European Commission launched a call for proposals for a two-year training programme for intervention epidemiologists in the European Union in 1994. Responding to this, experts from several national institutes for Public Health came together and the 2-year European Programme for Intervention Epidemiology Training (EPIET) was set up, starting in 1995, taking the Epidemic Intelligence Service (EIS) training programme of the United States' Centers for Disease Control and Prevention (US CDC) as an example [1,2]. The EPIET curriculum is set up to deliver independent, mid level epidemiologists with skills in the areas of surveillance, outbreak investigations, field-based epidemiological studies, scientific communication and teaching. The programme was integrated into the European Centre for Disease Control and Prevention (ECDC) in 2007. The set up and specific training objectives are described elsewhere in this journal [3].

The first cohort of EPIET fellows started in September 1995 and soon after, in January 1996, the German National Field Epidemiology Training Programme (FETP) at the Robert Koch Institute $(\mathrm{RKI})$ in Berlin was established as a national training programme associated with EPIET [4,5]. From the start of the German FETP (currently renamed into German Postgraduate training for Applied Epidemiology, PAE), there has been a strong interaction with EPIET, since the association includes sharing scientific coordinators and core teaching modules [4,5]. After this, other countries: Norway, Austria, Finland, Slovenia, followed linking national training activities to the EPIET programme which are referred to as EPIET-associated programmes [3]. These programmes are required to employ fellows in an acknowledged EPIET training site and to use selection criteria and daily working activities that are similar to the EPIET.

In December 2008 the European Commission published a Green Paper on the European Workforce for Health highlighting the problem of shortages in health professions, including public health, now and in the near future [6]. The strengthening of public health capacity through training has been defined by the ECDC as a strategic target in the multi-annual programme 2007-2013 [7].

In order to demonstrate the contribution of the EPIET and EPIET-associated programmes to the public health workforce in the EU Member States and Norway, we analyse activities and outputs of fellows from cohorts 1 to 12 (October 1995- September 2008), and describe the employment history of graduates after the training. Since there are strong links in programme content, philosophy and scientific review between EPIET and EPIET-associated programmes, we chose to analyse these programmes together.

\section{Material and methods}

We used the EPIET programme office archives to compare the curriculum of the programme, including training objectives and composition of short training modules. throughout the cohorts. The concept of 'site' also needed defining. A site is considered acknowledged by EPIET when it employs at least one senior epidemiologist that participated in training-of-trainer activities, including facilitation at the three week introductory course for new fellows. Information on training-of-trainers and the number of external participants to EPIET training activities was extracted from the database described below.

The contribution of the EPIET and EPIET- associated programmes was defined and measured in terms of the number of people trained, the number of peer-reviewed publications published on work performed during the training, the number of participations 
in international missions and the type of employment taken up after training. The output of all fellows has been registered in a 'pedagogical database', including publications (in the categories peer reviewed journals, bulletins, reports, abstracts and other), attendance to modules and projects, participation in international

TA B L E 1

Training modules developed within the EPIET curriculum

\begin{tabular}{|l|c|}
\hline Name of the module & Currently in use \\
\hline Communication and dealing with the press & \\
\hline Communication and scientific writing & $\mathbf{x}$ \\
\hline Computer tools in outbreak investigations & $\mathbf{x}$ \\
\hline Data management & \\
\hline Geographical information systems (GIS) & \\
\hline Logistic regression & \\
\hline Time series and logistic regression & $\mathbf{x}$ \\
\hline Multivariable analysis & \\
\hline Rapid assessment and deliberate release threats & $\mathbf{x}$ \\
\hline Rapid assessment in complex emergencies & $\mathbf{x}$ \\
\hline Time series analysis & $\mathbf{x}$ \\
\hline Training-of-trainers & \\
\hline Vaccinations & \\
\hline
\end{tabular}

field missions, graduation results and abstracts presented at conferences. Information regarding publications was reported by the fellows using the quarterly reports or incremental progress reports. This information was complemented with a PubMed® search for publications of work performed during the fellowship. Data on publications were stored in EndNote ${ }^{\circledR}$ version X.0.2.

To track current employment, we used data on employment after graduation as registered in a database by the EPIET Alumni Network (EAN). These data were provided by alumni themselves using a structured form in MS Excel. Missing employment information was collected using web-based social networks such as LinkedIn ${ }^{\circledR}$ and FaceBook ${ }^{\circledR}$ and using affiliation information from publications retrieved through Medline ${ }^{\circledR}$.

We also analysed the costs of the EPIET programme, using budget data from the 2002-2005 financial reports sent by the budget holder to the European Commission. Finally we used information from the ECDC budget for training 2006-2009 to calculate the costs to train one person during a one-week course. Data were analysed using MS Excel and MS Access.

\section{Results}

\section{EPIET curriculum through the years}

The ratio of theoretical teaching versus supervised training has remained unchanged throughout the years; a maximum of 10 weeks

F I G U R E 1

Number of fellows sent and hosted in EPIET and EPIET-associated programmes, by country, cohorts 1-12, 1995-2008 (n=161)

Number of fellows

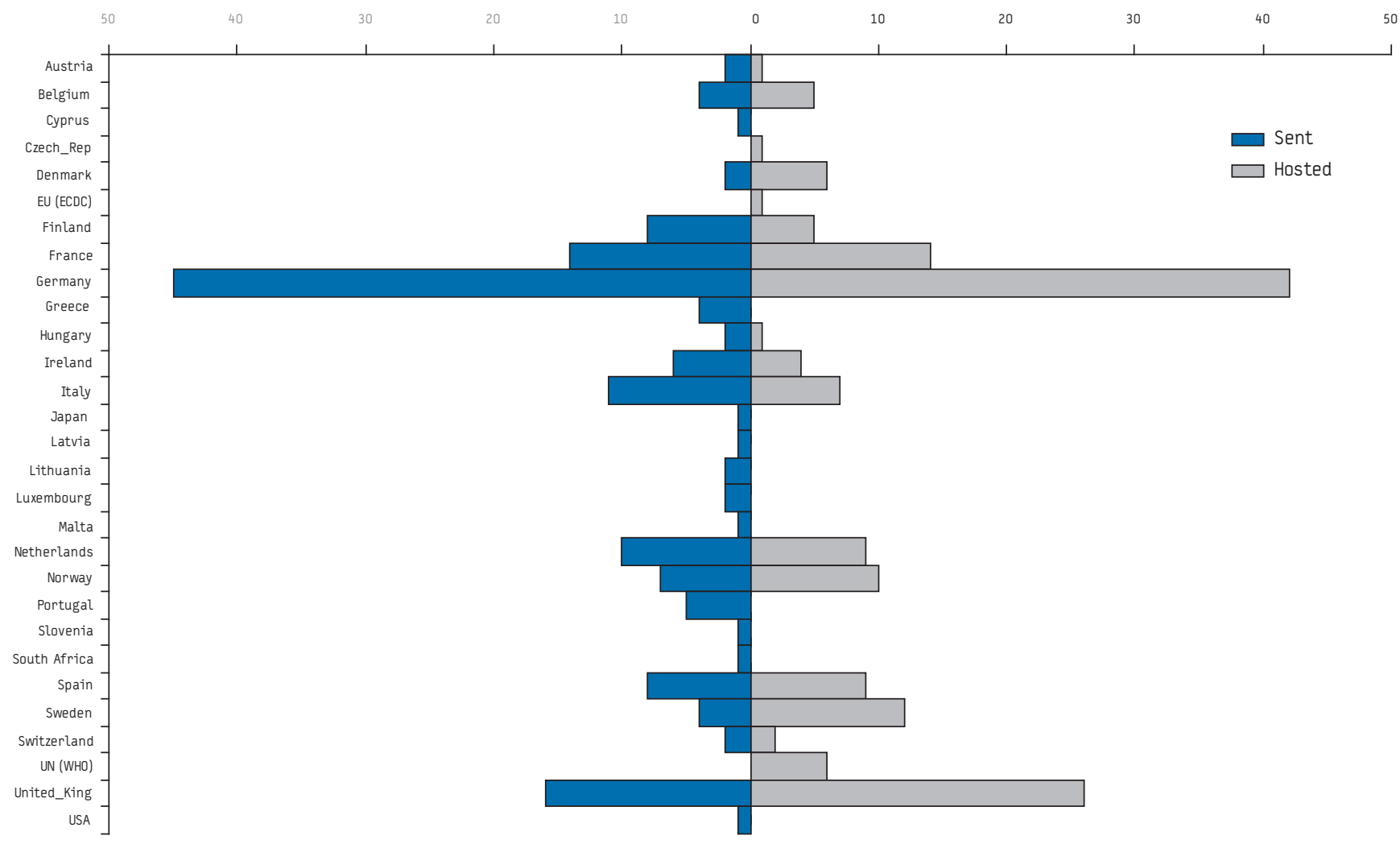


of teaching in modules and courses versus 22 months of supervised work at the training site or during field missions.

In total 13 short training modules, of which six are currently included in the curriculum, were developed for the EPIET between 1995 - 2008 (cohort 1-12) (Table 1). All training materials and training module curricula developed within the EPIET network are

F I G U R E 2

Publications in Medline from EPIET and EPIET-associated programme fellows from fellowship projects, January 1996-April $2009(n=340)$

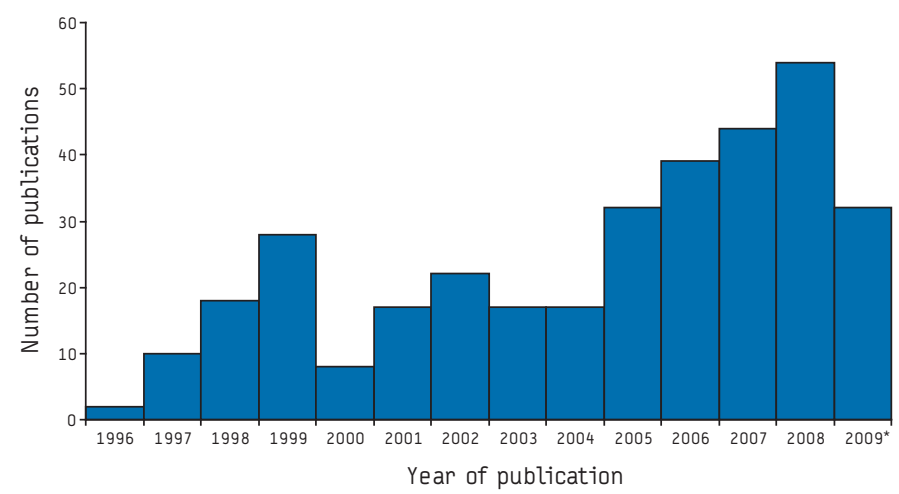

*Publications until 10 April

TA B L E 2

Top-10 topics in peer-reviewed publications from EPIET and EPIET-associated programme fellows from fellowship projects, 1996-2009 (as of 10 April)

\begin{tabular}{|l|c|}
\hline Topic of the study & Number of publications \\
\hline Salmonellosis & 33 \\
\hline Measles & 16 \\
\hline Norovirus / Norwalk-like agent & 13 \\
\hline Hepatitis A virus infections & 12 \\
\hline Campylobacteriosis & 11 \\
\hline Meningococcal disease & 11 \\
\hline Influenza & 10 \\
\hline Shigellosis & 9 \\
\hline E.coli 0157 & 7 \\
\hline Mumps & 7 \\
\hline
\end{tabular}

\section{T A B L E 3}

Level of employment of EPIET and EPIET-associated programme graduates, in first and current employment, cohort 1-12, 1996-2008

\begin{tabular}{|l|r|r|}
\hline Level of employment & First job (N=140) & Current job (N=139) \\
\hline International public health & $29 \%$ & $33 \%$ \\
\hline National public health & $46 \%$ & $44 \%$ \\
\hline Regional public health & $14 \%$ & $13 \%$ \\
\hline Private sector & $4 \%$ & $5 \%$ \\
\hline Other & $6 \%$ & $5 \%$ \\
\hline
\end{tabular}

available to FETP-like training programmes. Since the migration of EPIET to ECDC, these modules have served as templates to develop short courses for EU Member States [8].

\section{EPIET training sites and trainers}

In 2008, twenty-four training sites in 16 different countries were acknowledged by EPIET: Austria, Belgium, the Czech Republic, Denmark, Finland, France (3 sites), Germany (3 sites), Hungary, Ireland, Italy, the Netherlands, Norway, Spain, Sweden, Switzerland and the United Kingdom (5 sites). Recently however, the sites in the Czech Republic and Hungary were inactivated as supervisors moved to other employment.

During the first 12 cohorts 268 professionals from 66 different organisations participated as facilitator in EPIET modules and courses. On average, a facilitator returned twice to teach. Most facilitators (189) were employed at public health institutes at national, regional or local level in the EU who participated without requiring teaching fees. A minority of facilitators were private consultants (23) hired to teach highly specific technical topics. The remaining facilitators (56) were employed by public health institutes outside the EU, universities, NGO's or the ECDC and also donated their time and expertise for free. Approximately one third of the trainers in EPIET started teaching through a 'training of trainers' activity such as the preparation week of the introductory course, or through supervised teaching by more senior trainers in specific modules.

\section{Cohorts 1-12, 1995-2008}

Fellows, projects and publications

In cohorts 1-12, a total of 161 fellows entered the training: 121 in EPIET and 40 in EPIET-associated programmes. Of 27 EU countries plus Norway, 22 have sent fellows to the programmes and 15 have hosted fellows in acknowledged EPIET training sites. In addition, fellows have been trained at EPIET sites in Switzerland, at the ECDC, at the World Health Organization (WHO) Lyon office and at the WHO Headquarters Geneva (Figure 1). The EPIET diploma was awarded to 149 fellows. Reasons for not receiving the diploma included failure to achieve the EPIET training objectives and terminating the training prematurely.

The European Commission (DG SANCO) funded 61 of the 121 EPIET salaries, nine were funded by ECDC, four by the WHO and one by Switzerland. The remaining 46 salaries were funded by Member States.

Fellows engaged in projects in all areas of surveillance, in outbreaks and field investigations have produced 340 publications in 71 different peer-reviewed, Medline-listed journals (Figure 2). These publications appeared in Eurosurveillance (114), Epidemiology and Infection (47), Emerging Infectious Diseases (22) and the Lancet (11). A number were published in general infectious diseases journals (35) and in national journals (23). Eleven articles were published in journals in the domain of microbiology.

The top 10 topics of the 340 publications include mainly foodand waterborne diseases and vaccine preventable diseases (Table 2).

\section{International missions}

Fellows were requested to participate in missions by various international organisations: WHO (regional office Europe [EURO], Geneva Headquarters and Regional Office for the 
Eastern Mediterranean [EMRO], Caribbean Epidemiology Center [CAREC]), the ECDC, Epicentre, the Nordic Council, US CDC and the Norwegian National Institute for Public Health (FHI). To date, 70 fellows have been sent to 98 individual assignments 65 missions on behalf of the EU. Assignments included 32 outbreak investigations, one risk assessment, 17 surveillance projects, nine epidemiological surveys, four teaching and two other types of missions in 45 different countries, seven EU and EEA/EFTA, seven other European, 17 African, 10 Asian and four in South America. The pedagogical coordination of these missions was managed by the team of EPIET Scientific Coordinators, on occasion jointly with programme directors of the national field epidemiology training programmes in Canada, Germany and Spain.

\section{Career track after graduation}

We retrieved information on the first employment after graduation for 140 of the 149 graduates from cohorts $1-12$ who received an EPIET diploma. For 139 alumni we were also able to retrieve the current employment. The vast majority of graduates (90\%) take up a position and remain employed in applied public health, either on regional, national or international level (Table 3). Jobs in the private sector include consultancy and working with epidemiology in pharmaceutical companies. The category 'other' jobs include teaching.

Overall, $65 \%$ of the graduates currently have the same employer as immediately after their graduation. Of the 139 EPIET graduates where information on current employment is available, 27 are working in the public health sector outside the EU, including 13 working in Switzerland for international organisations (such as WHO, the United Nations High Commissioner for Refugees [UNCHR] and Médecins Sans Frontières [MSF])(Table 4). In terms of organisational position, one graduate is director of an international public health organisation, two coordinate EU disease specific networks, six are scientific coordinators of various FETP's and six are heads of unit.

\section{Costs of EPIET}

The costs per cohort of EPIET based on analysis of four cohorts (8-11, 2002-2005), ranged from 2.3 (cohort 8) to 3.2 million EUR (cohort 11), totalling 10.8 million EUR. These costs included 4.96 million EUR contributed by EU Member States in the form of salary costs for facilitators and supervisors and by hosting EPIET modules and courses. These contributions of the Member States were not

TA B L E 4

Geographical location (country/continent) of current employment of EPIET graduates and EPIET-associated programme graduates, cohort 1-12, $1996-2008$

\begin{tabular}{|c|c|c|c|c|c|c|c|}
\hline \multirow[t]{2}{*}{ Country of employment } & \multicolumn{3}{|c|}{ Public health } & \multirow[t]{2}{*}{ Private industry } & \multirow[t]{2}{*}{ Other } & \multirow[t]{2}{*}{ Total } & \multirow[t]{2}{*}{ Number of sent fellows } \\
\hline & International & National & Regional & & & & \\
\hline Austria & & 1 & & & & 1 & 2 \\
\hline Belgium & & & & 1 & & 1 & 4 \\
\hline Denmark & 3 & 3 & & & & 6 & 2 \\
\hline Finland & & 4 & & & & 4 & 8 \\
\hline France & 5 & 7 & 2 & 3 & & 17 & 13 \\
\hline Germany & 2 & 12 & 5 & & 2 & 21 & 42 \\
\hline Greece & & 3 & & & & 3 & 3 \\
\hline Hungary & & 1 & & & & 1 & 2 \\
\hline Ireland & & 1 & 2 & & & 3 & 6 \\
\hline Italy & 1 & 2 & & & & 3 & 11 \\
\hline Lithuania & & 1 & & & & 1 & 2 \\
\hline Luxembourg & 1 & & & & & 1 & 1 \\
\hline Malta & & 1 & & & & 1 & 1 \\
\hline Netherlands & 1 & 3 & 1 & & & 5 & 10 \\
\hline Norway & & 5 & & & & 5 & 5 \\
\hline Portugal & 1 & 2 & 1 & & & 4 & 4 \\
\hline Spain & & 1 & & & 1 & 2 & 7 \\
\hline Sweden & 11 & 1 & 1 & 1 & 1 & 15 & 4 \\
\hline United Kingdom & 2 & 4 & 6 & 2 & 3 & 17 & 16 \\
\hline Subtotal EU & 27 & 52 & 18 & 7 & 7 & 111 & 143 \\
\hline Africa & 1 & 2 & & & & 3 & \\
\hline Asia & 4 & 4 & & & & 8 & \\
\hline Caribbean & & 1 & & & & 1 & \\
\hline Europe & 13 & & & & & 13 & \\
\hline North America & & 2 & & & & 2 & \\
\hline South America & & 1 & & & & 1 & \\
\hline Subtotal non-EU & 18 & 10 & & & & 28 & \\
\hline
\end{tabular}


reimbursed from the EPIET budget, yet they were a condition in the grant agreements on EPIET with the European Commission: Member States were expected to contribute approximately $40 \%$ of the total costs for EPIET.

From cohorts 8-11, 62 EPIET fellows were trained and external participants joined for 226 person-weeks in EPIET modules and courses. The average cost per year to train an EPIET fellow therefore is 88,300 EUR. This amount includes the total salary costs, which are on average 60,000 EUR per year, including all additional costs for the employer such as taxes, social security fees and insurance. This means that the annual costs exclusively attributed to the training of one EPIET fellow, when excluding salary, is 28,300 Euro. This includes participation to modules and courses (travel, accommodation, per diem, calculated salaries of the facilitators), costs of the salaries for EPIET scientific coordinators, EPIET Programme office and the salary of the supervisors on site.

In comparison, the average cost to train a participant during a one-week ECDC course is approximately 2,700 EUR, including trainer fees, flights, accommodation, meals and per diem.

\section{Discussion}

We present the result of an objective exploitation of available data to describe the contribution of EPIET to public health workforce. A thorough impact analysis of the programme will be provided in the near future through an external evaluation of EPIET, which will focus on elements of the programme such as quality, appropriateness, required capacity to train, costs, administration and organisation.

The curriculum of EPIET has remained focussed on structured, supervised skills development (learning by doing). The knowledgebased teaching (modules and courses) has evolved through the years with the development of specific teaching modules, which possibly reflects the ability of the programme to adapt to changes in the competence requirements of intervention epidemiologists.

The high proportion of graduates working in public health in the EU reflects the successful achievement of the programme's objectives. EPIET contributes to the key objective of the Green Paper on Workforce for Health [6] to 'achieve self sufficiency at EU level' and to 'promote circular movement of staff moving to another country for training and returning with additional experience and skills'.

Our data show that the top-five countries benefitting from employment of the highest numbers of EPIET graduates are Germany, France, United Kingdom, Sweden and Denmark. This most likely reflects a mix of factors such as nationality of those who entered the programme ('fellows sent'), availability and number of EPIET training sites and job opportunities. Germany heads the list, probably because of the national PAE, which is included in this analysis. In addition, the United Kingdom, Germany and France have the highest number of EPIET training sites within in the country, which may also be an indicator of employment opportunities after graduation. Three countries employ less than one third of the number of EPIET fellows they have sent to cohorts 1 to 12: Belgium, Italy and Spain. There is no obvious explanation for this observation, though this may also be linked to relatively fewer employment opportunities for EPIET graduates as compared to other EU Member States. So far, only three of the 12 EU Member States that joined the EU since 2004 employ EPIET graduates.
Since cohort 12 (2006), an additional two 'new' EU Member States opened EPIET acknowledged training sites, but two operating sites were inactivated since cohort 12 due to trained supervisors taking up other employment. Even though the current cohorts in training include fellows from nine of the 'new' Member States, it will still take a while before job opportunities for EPIET graduates will be at the level of 'old' Member States.

One of the major challenges for training the public health workforce is the retention of professionals in countries with limited job opportunities or wages significantly below the EU average. Strategies to fill this gap may include development of more EPIET-associated programmes in new Member States and increased efforts to identify new supervisors to join the EPIET training-of-trainers programme. The number of fellows that needed to be trained each year to address the needs of public health in the EU will be addressed in the external evaluation of EPIET. At this stage we observe that the size of the latest EPIET cohort, cohort 15 consisting of 29 fellows including fellows from EPIETassociated programmes, is less than half the number of EIS officers recruited yearly in the US programme, while the EU population is significantly larger.

The increase of scientific output of the EPIET fellowship keeps the pace of the increase in size of the cohorts, with the areas of food- and waterborne diseases, vaccine preventable diseases, influenza and meningococcal disease among the most frequently published topics. The majority of articles were published in the 'Eurosurveillance' and 'Epidemiology and Infection' journals. We are aware that scientific publications provide a very limited indicator of a programme's performance, however this was the most convenient and complete set of data available for analysis. For future analysis it would be useful to look into citation indices and impact factors of the journals. In addition, it could be considered by the programme to create an indicator of public health actions that were the consequence of the work performed by fellows.

The costs to train one EPIET fellow should be seen in the light of the programme approach, which is learning by doing. The fellow works at an institute at least at the level of a junior scientist and is available for $90 \%$ of the working time when corrected for absence for modules and conferences. Therefore, the salary costs of an EPIET fellow should not be considered as costs for training but as similar to the cost for employing a public health professional.

In addition to the measurable outcomes of the EPIET training as mentioned in the results, the side benefits of the EPIET training are to be found in the training-of-trainers approach of the programme towards new facilitators and supervisors and the opportunity for external participants to training modules and courses when spare seats are available. For each fellow, at least three external participants were accepted in EPIET modules without charge and the fact that 24 training sites cooperate with the scientific coordinators to deliver consistency in methods of applied epidemiology, thus achieving 'one professional language' and tangible professional bonds between institutes. This 'professional bonding' is considered an important outcome of the programme, which is difficult to measure [9]

In conclusion, we believe that the EPIET programme is successful in achieving the programme objectives by developing a European Network of Intervention Epidemiologists practicing uniform methods, by developing a capacity to respond to public 
health crisis in and beyond Europe and by strengthening the workforce in communicable disease surveillance and control in EU Member States.

Though many countries around the world have national FETP, the character of EPIET is rather unique in the sense that it is shared by 27 Member States as a joint effort for capacity building through training. After the two-year training, graduates are able to apply the relevant competencies in cross-border activities, addressing the specific challenges that communicable disease control poses at the European level. The fact that such a network of epidemiologists has been trained in one language (both professionally as linguistic) offers a great advantage in the joint response to disease control in Europe.

\section{Acknowledgements}

German, Finnish, Norwegian and Austrian FETP's for making data available on alumni from the fellows linked to EPIET. Ana-Belen Escriva for her advice on the analysis of publications, Viviane Bremer, Carmen Varela Santos, Vladimir Prikazsky for their critical review of the drafts of this article.

\section{References}

1. Moren A, Drucker J, Rowland M, Van Loock F., [European Program for Intervention Epidemiology Training (EPIET): a training epidemiologic intervention in Europe]. Rev Epidemiol Sante Publique, 1998; 46(6): p. 533-40. French.

2. van Loock F, Rowland M, Grein T, Moren A. Intervention epidemiology training: a European perspective. Euro Surveill. 2001;6(3):pii=218. Available from: http:/l www.eurosurveillance.org/ViewArticle.aspx?ArticleId=218

3. Bremer V, Bosman A, Coulombier D. New perspectives after the transition of EPIET to ECDC -the future of the programme. Euro Surveill. 2009; 14(42): pij=19374. Available from: http://www.eurosurveillance.org/ViewArticle. aspx?ArticleId $=19374$

4. Ammon A, Hamouda O, Breuer T, Petersen LR. The Field Epidemiology Training Program (FETP) in Germany. Euro Surveill. 2001;6(3):pij=219. Available from: http://www.eurosurveillance.org/ViewArticle.aspx?ArticleId=219

5. Bremer V. [Infectious disease epidemiology education and training Programs. FETP and EPIET] Bundesgesundheitsblatt Gesundheitsforschung Gesundheitsschutz 2005; 48(9): p. 1049-54. German.

6. European Commission. Green Paper On the European Workforce for Health Brussels: 2008. Available from: http://ec.europa.eu/health/ph_systems/docs/ workforce_gp_en.pdf

7. European Centre for Disease Prevention and Control (ECDC). Strategic multiannual programme 2007-2013: Public health activities, disease-specific programmes and multilateral partnerships. 2006. Available from: http:// www.ecdc.europa.eu/en/aboutus/Key\%20Documents/07-13_KD_Strategic_ multiannual_programme.pdf

8. Editorial team. Training courses for communicable disease outbreak investigation: ECDC call for tender. Euro Surveill. 2006;11(33): p. 3029. Available from: http://www.eurosurveillance.org/ViewArticle.aspx?ArticleId=3029

9. Krause G, Stefanoff P, Moren A., Applied Epidemiology Training in Europe: quite a success - but more to be done. Euro Surveill. 2009; 14(42):pii=19375. Available from: http://www.eurosurveillance.org/ViewArticle.aspx?ArticleId=19375 